\title{
“Estrogens and the Heart: Do they Help or Hurt?" How Estrogen impacts the Cardiovascular System
}

\author{
Maria Grazia Modena* \\ University of Modena and Reggio Emilia, School of Medicine, Department of Surgery, Medicine, Dentistry and \\ Morphological Sciences, Modena Italy
}

Received: May 31, 2016; Accepted: June 23, 2016; Published: June 28, 2016

*Corresponding author: Maria Grazia Modena, University of Modena and Reggio Emilia, School of Medicine, Department of Surgery, Medicine, Dentistry and Morphological Sciences, Modena Italy; Tel no: +39-059/244218; E-mail: mariagrazia.modena.@unimore.it

\begin{abstract}
Extensive epidemiological observations, clinical mechanistic studies, and basic laboratory research have suggested that the incidence of Cardiovascular Disease (CVD) increases with menopause and that Hormone Replacement Therapy (HRT), or more specifically Estrogen Replacement Therapy (ERT), is associated with beneficial cardiovascular effects in postmenopausal women. Estrogen has a multitude of biological effects that may account for its apparent cardiovascular protection, including favourable effects on the lipid profile, antioxidant activity, enhanced fibrinolysis, and a series of actions on the vasculature. However, because estrogen affects so many cellular processes, it is imperative to gain a better understanding of the molecular mechanisms, both genomic and non-genomic, by which estrogen induces cellular signals and modulates vascular responses. While there is no question that HRT effectively mitigates troublesome menopause symptoms, conflicting evidence about other effects of HRT has fuelled controversy concerning its relative benefits and risks. Moreover, it could seem that CVD protection mediated by replacement therapy is maximum when the therapy was initiated in the absence of signs of atherosclerosis (typically in premenopause) while it vanishes as atherosclerosis proceeds (in the postmenopausal patient). In addition, many questions remain regarding the effectiveness of type of hormonal compounds, doses, regimens, route and, mainly, on time of administration. There are data from recent literature that early menopause and not menopause per se, is a risk factor for CVD and that early ERT may have a role on delaying the atherosclerosis process in postmenopausal women. We conclude that is not time yet to close the chapter of the role of estrogens in the postmenopausal phase of Research, in fact, in this area has begun again.
\end{abstract}

Keywords: Estrogen; Postmenopause; Heart; Cardiovascular disease; Hormonal Replacement Therapy

\section{Abbreviations}

CVD: Cardiovascular disease; HRT: Hormone replacement therapy; ERT: Estrogen Replacement Therapy; E2: $17 \beta$-estradiol; ER- $\alpha$ : estrogen receptor- $\alpha$; ER- $\beta$ : estrogen receptor- $\beta$; GPER: G Protein-coupled Estrogen Receptor; PGIS: Prostacyclin Synthase; COX: Ciclooxigenase; MCP: Monocyte Chemoattractant Protein; NO: Nitric Oxide; AT: Angiotensin; ACE: Angiotensin-converting enzyme; SHR: Spontaneously Hypertensive Rat; ET: Endothelin; MPA: Medroxyprogesterone Acetate; CEE: Conjugated Equine
Estrogens; HERS: Heart and Estrogen/progestin Replacement Stuy; ERA: Estrogen Replacement and Atherosclerosis; WEST: Women's Estrogen for Stroke Trial; WHI: Women Health Initiative trial; MWS: Million Women Study; EVTET: Estrogen in venous Thromboembolism Trial; ELITE: Early vs Late Intervention Trial with Estradiol; TNF: Tumor Necrosis Factor; IMT: Intima-Media Thickness;

\section{Introduction}

Extensive epidemiological observations, clinical mechanistic studies, and basic laboratory research have suggested that the incidence of cardiovascular disease increases with menopause and that Hormone Replacement Therapy (HRT), or more specifically Estrogen Replacement Therapy (ERT), is associated with beneficial cardiovascular effects in postmenopausal women. Estrogen has a multitude of biological effects that may account for its apparent cardiovascular benefits, including favourable effects on the lipid and glycemic profile, antioxidant activity, enhanced fibrinolysis, and a series of actions on the vasculature. The aim of this review is to analyze past and current literature related to mechanism of action of endogenous estrogens and main clinical studies on HRT in order to clarify if there is a future for estrogen replacement therapy in postmenopausal women. We will focus in this review mainly on estrogen, as the most studied sex hormone either from basic as well as from clinical research.

\section{Estrogens}

The major circulating estrogen is named $17 \beta$-estradiol (E2), mainly produced in the theca and granulose cells of the ovaries, but also locally through the conversion of testosterone by aromatase both in men and women. E2 binds equally to both specific receptors: estrogen receptor- $\alpha$ and estrogen receptor- $\beta$ (ER- $\alpha$, ER- $\beta$ ).

Estrogen has pleiotropic effects on the cardiovascular system $[1,2,3]$. The mechanisms by which estrogen confers these pleiotropic effects are still not completely known. Until a decade ago, all estrogen signalling was thought to occur by estrogens binding to estrogen receptors, which bind to DNA and function as ligand-activated transcription factors. Estrogen binding to the 
receptor alters gene expression, thereby altering cell function Figure 1.

Estrogen also binds to nuclear estrogen receptors that are tethered to the plasma membrane, resulting in acute activation of signalling kinases such as PI3K [2]. The nuclear response is much slower, as the ER-estrogen complex moves to the nucleus, where it functions as a transcription factor, both activating and repressing gene expression. Therefore, as is the case for other steroids, the effect of estrogen can be divided into two types: those that are delayed in onset and prolonged in duration are called "Genomic" effects, and those that are rapid in onset and short in duration are called "Non-Genomic" effects. The early effects take place within minutes (e.g. changes in vasomotor tone) and are mediated by rapid intracellular signalling pathways, whereas the delayed effects (e.g. remodelling or lipid alterations) require hours to days to occur and require transcriptional events with subsequent modulation of protein expression $[1,3,4,5,6,7,8]$. Measurements of mRNA for ER- $\alpha$ and ER- $\beta$ have shown distributions in the body that differ quite markedly from each other. Moderate to high expression of ER- $\alpha$ has been identified in the pituitary, kidney, epididymis, and adrenal glands, whereas moderate to high expression of ER- $\beta$ has been found in prostate, lung, bladder, and brain. Overlapping high expression of ER- $\alpha$ and ER- $\beta$ has been identified in ovary, testis and uterus. In the vasculature, ERs have been identified in the endothelium, intima and adventitia and on adrenergic nerve endings of arteries from various territories and several species including humans [1].

Recently, the G Protein-Coupled Estrogen Receptor (GPER) was identified as a novel estrogen receptor that mediates a rapid, non-genomic response to estrogens in diverse tissues, including the cardiovascular system .GPER stimulates cAMP production and calcium mobilization. In the study of De Francesco, the left ventricles of male Spontaneously Hypertensive Rats (SHR) express higher levels of GPER compared to normotensive Wistar Kyoto (WKY) rats. The GPER ligand G-1induced negative inotropic and lusitropic effects that could be considered as a protective action in stresfull condition such as hypertention and heart failure .The class of G-protein-coupled receptors (GPCRs) is one of the largest classes of receptors to be targeted for drug therapy [9].

Estrogens have a number of effects on cardiovascular function and disease, since they influence the inflammatory response, metabolism, insulin sensitivity, cardiac myocyte and stem cell survival, vascular tone.

\section{Estrogen's action on the Vasculature}

Estrogen acts both on vascular smooth muscle and endothelial cells where estrogen receptors have been identified [3]. Estrogen administration promotes vasodilation in humans and in

\title{
Estrogen Receptors in Normal Cells
}

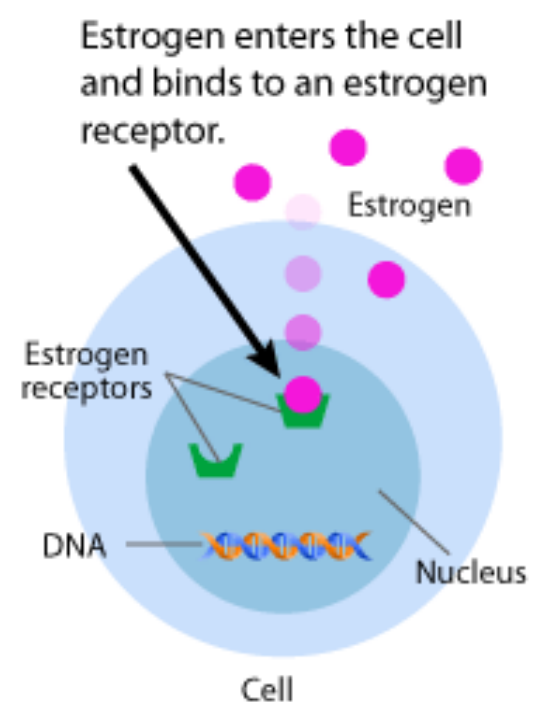

\author{
The receptor binds to \\ DNA which triggers cell \\ proliferation.
}

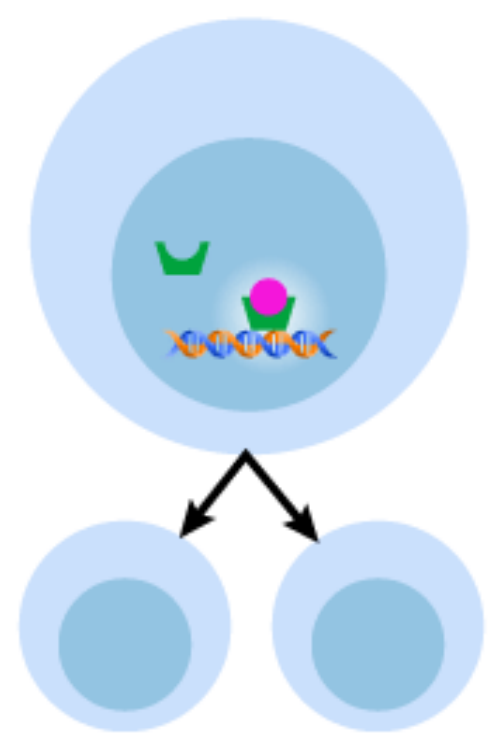

Figure 1: 
experimental animals, in part by stimulating Prostacyclin and nitric oxide synthesis, as well as by decreasing the production of vasoconstrictor agents such as Cyclooxygenase-derived products, reactive oxygen species, Angiotensin II, and endothelin-1. The endothelium plays a major role in vascular tone control by releasing both relaxing and contractile factors. Estrogens exert a number of effects on endothelial-derived factors, enhancing endothelial-dependent relaxation in arterial rings from different animals and from different vascular beds, including those in the coronary, mesenteric, aorta and cerebral arterial system $[1,8,10]$ It has been repeatedly shown that $17 ß$-estradiol stimulates production of vasodilator prostaglandins such as Prostacicline $\left(\mathrm{PGI}_{2}\right)$ in a variety of preparations $[10,11,12]$. Increased levels of $\mathrm{PGI}_{2}$ upon stimulation with estradiol have been associated with increased expression of the key enzymes involved in $\mathrm{PGI}_{2}$ production, such as phospholipase $\mathrm{A}_{2}$, ciclooxigenase-1 (COX1), and Prostacyclin Synthetase (PGIS), as demonstrated in rat cerebral blood vessels, where chronic in vivo 17ß-estradiol treatment enhances basal PGI ${ }_{2}$ synthesis by increasing COX-1 and PGIS proteins [11,13].

\section{Estrogen's impact on Inflammation}

Many cell types involved in immune and inflammatory responses are responsive to estrogen. These include $\mathrm{T}$ and $\mathrm{B}$ lymphocytes, and cells from the myelomonocytic lineage such as monocytes, macrophages, and mast cells. The actions of estrogen on inflammatory markers seem to depend on levels of estrogen. At physiological concentrations, estrogen increases proinflammatory cytokine production - IL-1, Tumor Necrosis Factor-a (TNF-a), and IL-6 - by monocytes. However, subjects with high estrogen status such as premenopausal women, have significantly lower Monocyte Chemoattractant Protein (MCP-1) levels than subjects with low estrogen status (postmenopausal women), and hormone replacement therapy lowers plasma levels of MCP-1 [14,15]. A prospective, randomized, placebo-controlled 12 -week study on healthy, normotensive postmenopausal women who received either micronized estradiol alone, or sequentially estradiol combined with a progestogen showed a significant decrease in the plasma concentrations of soluble ICAM-1, soluble VCAM-1, and thrombomodulin. Similarly, it has been shown that Fas ligand expression by the vascular endothelium, which inhibits the migration of inflammatory cells into the vessel wall, is improved by estradiol treatment, resulting in inhibition of leukocyte traffic across the endothelium [15]. According to the author, the maintenance of endothelial Fas ligand expression by estradiol may represent a mechanism of the apparent antiatherogenic effect of estrogens. Our group has reported that in postmenopausal women in addition to an increase in inflammation and in C-reactive protein, autoimmune diseases are much more frequent than in men of similar age. This phenomenon is described as "Inflammaging" and that autoimmune mechanism make a significant contribution to the genesis of coronary artery disease in women [16].

The vasculoprotective effects of estrogen have been also partially attributed to a shift in the NO/superoxide anion $\left(\mathrm{O}_{2}\right)$ balance in the vessel wall, thereby increasing the bioavailability of NO. Increased oxidative stress and decreased NO production due to estrogen deficiency have been associated with higher blood pressure levels [17]. Chronic estrogen replacement in ovariectomized rats prevents the decrease of plasma levels of nitrites/nitrates as well as the enhancement of blood pressure [18]. Several years ago we studied the effect of transdermal estrogen replacement therapy on hypertensive postmenopausal women. The addition of transdermal HRT to antihypertensive standard therapy, vs same treatment and placebo for HRT, was more successful in reduction of blood pressure and induced, only in the treated group, modification on metabolic and inflammatory profile [19].

\section{Impact of the estrogen on the renin-angiotensin system}

Estrogen acts on the Renin-angiotensin system at different points of the cascade: at the formation of Ang II, at the level of Ang II receptors and on Ang II-induced responses. It also effects on the levels of Renin in the circulation:

1) Women under hormone replacement therapy with estrogen display lower renin levels than controls,

2) Premenopausal women display lower renin levels than postmenopausal women, and

3) Women have lower renin levels than men [20,21,22]. Estrogen deficiency has been shown to increase the subtype 1 Ang II receptor (AT1 receptor) mRNA levels, as well as the impact of Ang II on vasoconstriction (due to increased AT1 receptor density), whereas estrogen replacement therapy in ovariectomized rats reversed AT1 receptor overexpression. $[23,24]$.

Estrogens also affect Angiotensin-Converting Enzyme (ACE) activity. Brosnihan, et al. [25] showed that ACE activity in the circulation and in tissues is reduced with chronic hormone replacement in two animal models of postmenopause. Clinical data have shown that postmenopausal women who received conjugated equine estrogen for 3 months exhibited a significant reduction in plasma ACE activity that correlated with an increase in NO-mediated forearm endothelium-dependent vasodilatation (reactive hyperemia) and increased serum levels of the nitrite/ nitrate ratio. Treatment with losartan, an AT1 antagonist, normalizes high blood pressure in $100 \%$ of female SHR against $53 \%$ of male SHR [26]. Enalapril, an ACE inhibitor, produced similar results, normalizing blood pressure in $71 \%$ of female SHR vs $46 \%$ of male SHR [27].

\section{Estrogen and the endothelial pathway}

Similar to its action on the Renin-Angiotensin system, the action of estrogen on the endothelin-1 (ET-1) pathway is apparent at different points of the cascade: at its formation, at the level of the receptors, and on ET-1- induced responses. Studies conducted on healthy postmenopausal women who received continuous hormone replacement therapy (17ß-estradiol combined with norethisterone acetate or methoxyprogesterone) showed that postmenopausal women treated with hormone replacement therapy had increased plasma nitrites/nitrates and decreased ET-1 levels [28]. 


\section{Impact of estrogen on myocardial electrophysiology}

Finally, there is recent data suggesting that sex hormones modulate cardiac repolarization, including hormonal effects on ion channels. The translational study of Anneken [29] assessed the relationship between QTc duration and gonadal hormones and the underlying mechanisms. Elevated estradiol levels were associated with shorter QTc intervals in healthy women and female LQT-2 patients. Estradiol acts on KCNH2 channels via enhanced estradiol-receptor-a-mediated Hsp90 interaction, augments membrane trafficking and thereby increases repolarizing current. These results provide mechanistic insights into hormonal control of human ventricular repolarization and open novel therapeutic avenues.

In summary there is evidence that estrogens act both in vascular smooth muscle, endothelial cells as well in the myocites and may exert their cardiovascular protective actions by direct effects on the vessel wall. Figure 2 summarizes all the potential vascular effects of this powerful steroid hormone. However, because estrogen affects so many cellular processes, we do not completely understand its mechanisms, both genomic and nongenomic, in inducing cellular signals and modulating different responses. This may be the key to explaining the apparently contradictory data regarding the use of this hormone in patients, with persistent lack of a final message that we will discuss in the second part of the review.

\section{Progestogens}

Progestogens are compounds which include not only the unique natural progestogen that is the progesterone but also a variety of synthetic progestogens [30,31]. The term "Progestogen" is currently used exclusively to describe synthetic progestogens such medroxyprogesterone acetate (MPA), levonorgestrel and norethindrone, and does not refer to natural progesterone. The synthetic hormones with progestational action are derived from three sources: natural progesterone, androgen and spironolactone [32]. Their metabolism is poorly understood; there are few studies on them mainly because few studies have be done about them. Administration is either oral (with a first-pass hepatic metabolism), or parenteral where hepatic metabolism also occurs, although it is not the first pass. One of the biggest differences among progestogens is their ability to bind to the various steroid receptors; in addition to their action on progesterone receptors, they can stimulate or block androgen, estrogen, glucocorticoids and mineralcorticoids receptors [33]. In postmenopausal women, progestogens are used as therapy to protect the endometrium from hyperplasia during estrogen therapy [33,34].

\section{Hormone Replacement Therapy}

For many years the conventional wisdom, backed by observational and epidemiological studies, has held that "replacement" of estrogen after menopause would maintain or restore the relative protection from cardiovascular disease enjoyed by premenopausal women as compared with men of similar age. Cardiovascular Diseases (CVD) are the leading cause of morbidity and mortality in men and women worldwide. Following menopause and loss of hormonal protection, genderbased differences in CVD are reduced, with the CVD risk being higher and more in women who develop the metabolic syndrome. In postmenopausal women, many features of the metabolic syndrome emerge with estrogen deficiency.

They exhibit:

1) Dyslipidemia (hypertriglyceridemia, reduced HDL, and increased small dense LDL particles);

2) Insulin resistance;

3) Hypertension;

4) Increased central fat and reduction in lean body mass; and

5) Increased hypercoagulability and pro-inflammatory state.

Early menopause has a negative impact on females. Controversies about the safety of different postmenopausal

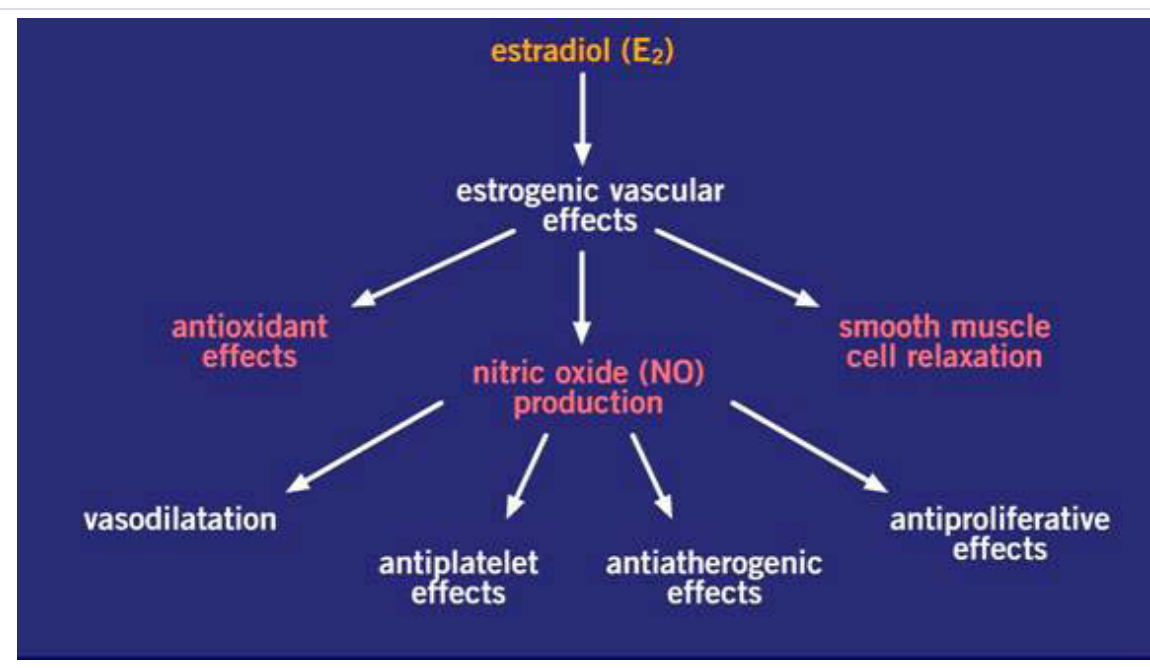

Figure 2: 
hormone therapies started 30 years ago and reached a peak in 2003 after the publication of the results from the Women's Health Initiative (WHI) trial and the Million Women Study (MWS) $[35,36]$. These and later studies failed to support a benefit of hormone-replacement therapy either for secondary prevention (HERS, ERA, WEST $[37,38,39,40]$ or primary prevention (WHI and MWS) of CVD. Variations in the route of estrogen administration in these trials may be one of the key reasons for conflicting results.

The single HRT formulation used in the WHI trial for non hysterectomized women was a combination of oral conjugated equine estrogens (CEE $-0.625 \mathrm{mg} / \mathrm{d}$ ) with a synthetic progestin, medroxyprogesterone acetate (MPA $-2.5 \mathrm{mg} / \mathrm{d}$ ). This compound increases the risks of venous thromboembolism, cardiovascular disease, stroke and breast cancer. The MWS, an observational study, showed an increased breast cancer risk in users of estrogens combined with either Medroxyprogesterone Acetate (MPA), norethisterone, or norgestrel. It is unclear to what extent the results of these studies can be extrapolated to other HRT regimens which differ in their doses, composition and administration routes, from the WHI and the MWS trials.

The metanalysis of 4 available randomized trials (HERS, EVTET, WEST and WHI ) indicates that the tested HRTs increased the risk of cardiovascular events as early as the first months of use in all postmenopausal women, regardless of age (although the data available on young, healthy, postmenopausal women starting HRT are missing), personal medical history, and ethnic origin [41]. This analysis concluded, moreover, that there was a similar risk in postmenopausal women for all the estrogens administered orally, CEE or $17 \beta$-estradiol, including the use of estradiol alone, without associated progestin, at the lower dose of $1 \mathrm{mg} / \mathrm{d}$. Hence, it would seem that use of these HRT formulations even at a low dose used for a short time is not proven to be safe. Similarly, available studies show no dose/effect relationship between different HRTs [42] and the risk of breast cancer. That risk may start to increase as soon as the first months of use, but the higher incidence may be attributable to the fact that women receiving HRT undergo more scrupulous screening for breast cancer, thus increasing the probability of detecting malignancies [43].

The first randomised trials on cardiovascular prevention resulted therefore in failure to confirm any cardiovascular benefit related to oral ET, with a homogeneous trend of the appearance of more frequent, more serious and earlier cardiovascular accidents in women taking oral formulations compared to those taking a placebo $[44,45,46]$. Why, in spite of laboratory and animal research which demonstrated a beneficial effect, doesn't the use of ERT in humans translate into a slowing of atherosclerosis progression? One possible explanation is in the increase in triglycerides and parallel decrease in LDL particle size, due to a pharmacological effect on liver metabolism which is quite different from the beneficial changes induced by normolipemic drugs [47]. These unanimously unwanted side effects include a rise in triglycerides, a drop in LDL particle size, an activation of coagulation and an increase in C-reactive protein reported also by our group [48,49,50,51]. With the non-oral route of administration, the observed effects are quite different; a decrease of triglycerides and LDL. There is a danger therefore, in spite of an anti-atherogenic effect; estradiol may increase the risk of venous and arterial thromboembolism. According to the main source of estrogen's beneficial effects is not due to its impact on the hepatocyte but the arterial endothelium [52,53] Consequently symptomatic postmenopausal women willing to start or continue hormonal treatment, a non-oral route of estradiol could be the considered for first-line prescription, especially in women at high risk of cardiovascular disease [54].

Finally, all the beneficial effects of HRT result more evident in hysterectomized women, since combination of estrogen and progesteron may account for some negative action on endothelial function due to the mineralcorticoid propoerty of progestogens and possible induction of hypertension.

\section{The risk of premature menopause for CVD}

The aim of this review is not to reiterate the guidelines for if and when hormone replacement therapy is recommended since they are quite well documented, but to argue that, because of the many conflicting data has resulted form previous studies, clinical trials on ERT are still (and should be) ongoing. It is reasonable to postulate that CVD protection mediated by replacement therapy is maximum when treatment is initiated in the absence of signs of atherosclerosis typically in the perimenopausal period. The protection offered by estrogen treatment vanishes as atherosclerosis progresses.

Relatively recent data in literature show that premature menopause, rather than physiological menopause per se, is a risk factor for CVD. The Framingham Study shows that women who undergo premature menopause (either naturally or surgically), have a higher likelihood of developing CVD [55]. In particular, women with menopause before age 45 , especially those subject to bilateral Oophorectomy, have a higher risk of CVD and mortality [56], a concept also confirmed by autopsy studies of women undergoing Oophorectomy [57].Therefore an important determinant in the development of CVD seems the be age of onset of menopause, which influences the cardiovascular risk profile and correlates with the development of subclinical atherosclerosis [58]. As noted in the Women's Health Initiative observational study, hysterectomy associated with oophorectomy is associated with a high risk for cardiovascular complications in the short and long term. Women who had undergone hysterectomy had a higher incidence of disease than obese, diabetic, hypertensive and/or hypercholestoremic individuals. They frequently reported history of myocardial infarction, stroke, revascularization by CABG or percutaneous coronary procedures, with an annual incidence of CVD 25\% higher than women with natural menopause. This was true in women undergoing hysterectomy alone and become even worse in those undergoing bilateral oophorectomy [59,60,61,62]. This increased mortality is mitigated by the use of adequate estrogen therapy, emphasizing the role of such therapy after hysterectomy. Moreover a careful analysis of WHI had shown how samples of 
women enrolled were not uniform and also quite old (as in the HERS trial). In fact, a re-analysis for subgroups of the WHI study suggested that early administration of treatment (within the first 10 years from onset of menopause) was associated with a reduced risk of CVD [62].

The observation of the importance of the "Timing Hypothesis" led, after years of silence on this field, to initiate clinical research once more on estrogen therapy to slow atherosclerosis progression. The most recent study is the ELITE trial, the "Early Vs Late Intervention Trial with Estradiol" and preliminary results were reported at the American Heart Association meeting this past November 2015.The ELITE trial [61] included 643 postmenopausal women who had prior hysterectomy. About half were close to the onset of menopause (less than 6 years) and about half were more distant from menopause (at least 10 years). The mean age of the first group was 55 years and the mean age of the second group was 65 years. The women were randomized to 17 beta-estradiol $1 \mathrm{mg}$ given orally each day versus placebo. The women who had an intact uterus also received 10 days of micronized progesterone gel vaginally. The outcome measure was carotid Intima-Media Thickness (IMT) measured by ultrasound. Over a period of up to 6 years, treated women in early menopause had slower progression of atherosclerosis measured by carotid IMT than the women randomized to placebo, whereas the group of older women did not show those differences, $(P=.007$ between younger and older treated groups) [62].

\section{Conclusions}

In our opinion estrogens may have great benefit in aging as a generic anti-inflammatory agent, since atherosclerosis is an inflammatory process, which, in fact, may be anticipated, almost exclusively in women, from autoimmune diseases. Clinical studies in humans have yielded results that are at a variance with those of more basic investigations, which showed a clear-cut benefit of estrogen treatment for the prevention and progression of atherosclerosis. This may be due to differences in study design: in animal studies estrogen treatment was used immediately or shortly after ovariectomy, while in some key clinical trials, estrogen was given years after menopause. Further basic research into the underlying molecular mechanisms of estrogen's actions is essential to provide a better understanding of the many effects of hormone and firm guidelines for its therapeutic use in humans of the many properties of this powerful hormone.

\section{References}

1. R.C. Tostes, D. Nigro, Z.B. Fortes, M.H.C. Carvalho. Effects of estrogen on the vascular system. Braz J Med Biol Res. 2003;36(9):1143-1158.

2. Kelly MJ \& Levin ER. Rapid actions of plasma membrane estrogen receptors. Trends Endocrinol Metab. 2001;12(4):152-156.

3. Murphy E. Estrogen Signaling and Cardiovascular Disease. Circulation Research. 2011;109:687-696

4. Bjornstrom L, Sjoberg M. Mechanisms of estrogen receptor signaling: convergence of genomic and nongenomic actions on target genes. Mol Endocrinol. 2005;19(4):833-842.

5. Hewitt SC, Deroo BJ, Hansen K, Collins J, Grissom S, Afshari CA, et al.
Estrogen receptor-dependent genomic responses in the uterus mirror the biphasic physiological response to estrogen. Mol Endocrinol. 2003;17(10):2070-2083.

6. Kang L, Zhang X, Xie Y, Tu Y, Wang D, Liu Z, et al. Involvement of estrogen receptor variant ERalpha36, not GPR30, in nongenomic estrogen signaling. Mol Endocrinol. 2010;24(4):709-721.

7. Grohe C, Kahlert S, Lobbert K, Vetter H. Expression of oestrogen receptor alpha and beta in rat heart: role of local oestrogen synthesis. J Endocrinol. 1998;156(2):R1-7.

8. Ihionkhan CE, Chambliss KL, Gibson LL, Hahner LD, Mendelsohn ME, Shaul PW. Estrogen causes dynamic alterations in endothelial estrogen receptor expression. Circ Res. 2002;91(9):814-820.

9. De Francesco EM, AngeloneT, Pasqua T, Pupo M, Cerra MC, Maggiolini M. GPER Mediates Cardiotropic Effects in Spontaneously Hypertensive Rat Hearts. 2013;8(8):e69322.

10.Zhu Y, Bian Z, Lu P, Karas RH, Bao L, Cox D, et al. Abnormal vascular function and hypertension in mice deficient in estrogen receptor beta. Science. 2002;295: 505-508.

11. Calkin AC, Sudhir K, Honisett S, Williams MR, Dawood T \& Komesaroff PA. Rapid potentiation of endothelium-dependent vasodilation by estradiol in postmenopausal women is mediated via cyclooxygenase 2 . Journal of Clinical Endocrinology and Metabolism. 2002;87(11):50725075 .

12. Dantas AP, Scivoletto R, Fortes ZB, Nigro D \& Carvalho MH. Influence of female sex hormones on endothelium-derived vasoconstrictor prostanoid generation in microvessels of spontaneously hypertensive rats. 1999;34(4):914-919.

13. Ospina JA, Krause DN \& Duckles SP. 17beta-estradiol increases rat cerebrovascular prostacyclin synthesis by elevating cyclooxygenase-1 and prostacyclin synthase. Stroke. 2002;33(2):600-605.

14. Koh KK, Son JW, Ahn JY, Lee SK, Hwang HY, Kim DS, et al. Effect of hormone replacement therapy on nitric oxide bioactivity and monocyte chemoattractant protein-1 levels. Int J Cardiol. 2001; 81(1):43-50.

15. Cid MC, Kleinman HK, Grant DS, Schnaper HW, Fauci AS \& Hoffman GS. Estradiol enhances leukocyte binding to tumor necrosis factor (TNF)stimulated endothelial cells via an increase in TNF-induced adhesion molecules E-selectin, intercellular adhesion molecule type 1 and vascular cell adhesion molecule type 1. J Clin Invest. 1994; 93(1):1725.

16. Leuzzi C, Sangiorgi GM, Modena MG. Gender specific aspects in the clinical presentation of cardiovascular disease. Fundamental \& Clinical Pharmacology. 2010;24(6):711-717.

17. Wagner AH, Schroeter MR, Hecker M. 17beta-estradiol inhibition of NADPH oxidase expression in human endothelial cells. FASEB J. 2001; 15:2121-2130.

18. Barbacanne MA, Rami J, Michel JB, Souchard JP, Philippe M, Besombes $\mathrm{JP}$, et al. Estradiol increases rat aorta endothelium-derived relaxing factor (EDRF) activity without changes in endothelial NO synthase gene expression: possible role of decreased endothelium-derived superoxide anion production. Cardiovasc Res. 1999;41(3): 672-681.

19. Modena MG, Molinari R,Muja N Jr, Castelli A, Pala F, Rossi R. Double blind randomized placebo-controlled study of transdermal estrogen replacement therapy on hypertensive postmenopausal women. Am J Hypertens. 1999;12:1000-1008.

20. Nickenig G, Strehlow K, Wassmann S, Baumer AT, Albory K, Sauer 
$\mathrm{H}$, et al. Differential effects of estrogen and progesterone on AT(1) receptor gene expression in vascular smooth muscle cells. Circulation. 2000;102(15):1828-1833.

21. Nickenig G, Baumer AT, Grohe C, Kahlert S, Strehlow K, Rosenkranz S, et al. Estrogen modulates AT1 receptor gene expression in vitro and in vivo. Circulation. 1998;97(22):2197-2201.

22. Higuchi S, Ohtsu H, Suzuki H, Shirai H, Frank GD, Eguchi S. Angiotensin II signal transduction through the AT1 receptor: novel insights into mechanisms and pathophysiology. Clin Sci (Lond). 2007;112(8):417428.

23. Li YQ, Ji H, Shen Y, Ding LJ, Zhuang P, Yang YL, et al. Chronic treatment with angiotensin AT1 receptor antagonists reduced serum but not bone TGFbeta1 levels in ovariectomized rats. Can J Physiol Pharmacol. 2009;87(1):51-55.

24. Yung LM, Leung FP, Yao X, Chen ZY, Huang Y. Reactive oxygen species in vascular wall. Cardiovasc Hematol Disord Drug Targets. 2006.6(1):1-19.

25. Brosnihan KB, Senanayake PS, Li P, Ferrario CM. Bi-directional actions of estrogen on the renin- angiotensin system. Brazilian Journal of Medical and Biological Research. 1999;32(4):373-381.

26. Silva-Antonialli MM, Fortes ZB, Carvalho MH, Scivoletto R \& Nigro D. Sexual dimorphism in the response of thoracic aorta from SHRs to losartan. General Pharmacology. 2000; 34(5):329-335.

27. Nigro D, Fortes ZB, Scivoletto R, Barbeiro HV \& Carvalho MH. Sexrelated differences in the response of spontaneously hypertensive rats to angiotensin-converting enzyme inhibitor. Endothelium. 1997;5(1):63-71.

28. Saitta A, Altavilla D, Cucinotta D, Nunziata M, Nicola F, Francesco C, et al. Randomized, double-blind, placebo-controlled study on effects of raloxifene and hormone replacement therapy on plasma NO concentrations, endothelin-1 levels, and endothelium-dependent vasodilation in postmenopausal women. Arteriosclerosis, Thrombosis, and Vascular Biology. 2001;21: 1512-1519.

29. Anneken L, Baumann S., Vigneault $\mathrm{P}$ Peter Biliczki, Corinna Friedrich, Ling Xiao, et al. Estradiol regulates human QT-interval: acceleration of cardiac repolarization by enhancedKCNH2 membrane trafficking European Heart J. 2016;37:640-650.

30.Stanzky FZ , Hapgood SW, Mishell DR, Winer S. Progestogens used in Postmenopausal Hormone Therapy: Differences in Their Pharmacological Properties, Intracellular Actions, and Clinical Effects. Endocrine Reviewes. 2013;34(2):171-208.

31. Stanczyk FZ, Henzl M. Use of the name "Progestogen". Contraception. 2001;64(1):1-2.

32. Stanzky FZ, Janet PH, Sharon W, Daniel RM. Progestogens in Postmenopausal HT; Endocrine Reviewes. 2013;34(2):171-208.

33. The North American Menopause Society: Role of progestogens in hormone replacement therapy for postmenopausal women: position and statement of the North American Menopause Society. Menopause. 2003.10:113-132.

34.Apgar BS. Greenberg G. Using progestogens in clinical practice. Am Fam Physician. 2000;62(8):1839-1846.

35. Writing Group for the Women's Health Initiative Investigations. Risks and benefits of estrogen plus progestin in healthy postmenopausal women. JAMA. 2002;288(3):321-333.

36. Breast cancer and hormone-replacement therapy in the Million
Women Study. Lancet. 2003;362(9382):419-427.

37. Hulley S, Grady D, Bush T, Furberg C, herrington D, Riggs B, et al. Randomized trial of estrogen plus progestin for secondary prevention of coronary heart disease in postmenopausal women. Heart and Estrogen/progestin Replacement Study(HERS) Research Group. JAMA. 1998;280(7):605-613.

38. Hulley S, Furberg C, Barrett-Connor E, Cauley J, Grady D, Haskell W, et al. Noncardiovascular disease outcomes during 6.8 years of hormone therapy. Heart and Estrogen/progestin Replacement Study follow-up (HERS II). JAMA. 2002;288(1):58-66.

39. Hoibraaten E, Qvigstad E, Arnesen H, Larsen S, Wickstrøm E, Sandset PM. Increased risk of recurrent venous thromboembolism during hormone replacement therapy results of the randomized, doubleblind, placebo-controlled estrogen in venous thromboembolism trial. Thromb Haemost. 2000;84(6):961-967.

40. Viscoli CM, Brass LM, Kernan WN, Sarrel PM, Suissa S, Horwitz RI. A clinical trial of estrogen replacement therapy after ischemic stroke. N Eng J Med. 2001;345(17):1243-1249.

41. Beral V, Banks E, Reeves G. Evidence from randomised trials on the long-term effects of hormone replacement therapy. Lancet. 2002;360(9337):942-944.

42. Collaborative Group on Hormonal Factors in Breast Cancer. Breast cancer and hormone replacement therapy: collaborative reanalysis of data from 51 epidemiologic studies of 52705 women with breast cancer and 108411 women without breast cancer. Lancet. 1997;350(9084):1047-1059.

43. Geller ML, Chlebowski RT. HT and breast cancer risk. Sex Reprod Menopause. 2003;Suppl 4:5-9.

44. The Writing Group of the PEPI Trial. Effects of estrogen or estrogen/ progestin regimens on heart disease risk factors in postmenopausal women. JAMA. 1995;273(3):199-208.

45. Caine YG, Bauer KA, Barzegar S, ten Cate H, Sacks FM, Walsh BW, et al. Coagulation activation following estrogen administration to postmenopausal women. Thromb Haemostas. 1992;68(4):392-395.

46. Petitti D. Hormone replacement therapy for prevention: more evidence, more pessimism. JAMA. 2002;288(1):99-101.

47. Shlipak MG, Chaput LA, Vittinghoff E, Lin F, Bittner V, Knopp RH, et al. Lipid changes on hormone therapy and coronary heart disease events in the Heart and Estrogen/progestin replacement study (HERS). Am Heart J. 2003;146(5):870-875.

48. Wakatsuki A, Okatani Y, Ikenoue N, Fukaya T. Different effects of oral conjugated equine estrogen and transdermal estrogen replacement on size and oxidative susceptibility of low-density lipoprotein particles in postmenopausal women. Circulation. 2002;106(14):1771-1776.

49. Vehkavaara S, Silveira A, Hakala-Ala-Pietila T, Virkamäki A, Hovatta O, Hamsten A, et al. Effects of oral and transdermal estrogen replacement therapy on markers of coagulation, fibrinolysis, inflammation and serum lipids and lipoproteins in postmenopausal women. Thromb Haemost. 2001;85(4):619-625.

50. Decensi A, Omodei U, Robertson C, Bonanni B, Guerrieri-Gonzaga A, Ramazzotto F, et al. Effect of transdermal estradiol and oral conjugated estrogen on C-reactive protein in retinoid-placebo trial in healthy women. Circulation. 2002;106(10):1224-1228.

51. Modena MG, Bursi F, Fantini G.,Rossi R, Cagnacci A, Carbonieri, et al. Effects of hormone replacement therapy on C-reactive protein levels in healthy postmenopausal women: comparison between oral and 
transdermal administration of estrogen. Am J Med. 2002;113(4):331334.

52. Iwakura A, Luedemann C, Shasrty S, Hanley A, Kearney M, Aikawa R, et al. Estrogen-mediated, endothelial nitric oxide synthase-dependent mobilization of bone marrow-derived endothelial progenitor cells contributes to reendothelialization after arterial injury. Circulation. 2003;108(25):3115-3121.

53. Modena MG, Sismondi P, Mueck AO, Kuttenn F, de Lignieres B, Verhaeghe J. The TREAT Collaborative Study Group New evidence regarding hormone replacement therapies is urgently required. Transdermal postmenopausal hormone therapy differs from oral hormone therapy in risks and benefits. Maturitas. 2005;52(1):1-10.

54. Kannel WB, Hjortland MC, McNamara PM, Gordon T. Menopause and risk of cardiovascular disease: the Framingham study. Ann Intern Med. 1976;85(4):447-452.

55. Atsma F, Bartelink ML, Grobbee DE, van der Schouw YT. Postmenopausal status and early menopause as independent risk factors for cardiovascular disease: a meta-analysis. Menopause. 2006;13(2):265-279.

56. Rivera CM, Grossardt BR, Rhodes DJ, Brown RD Jr, Roger VL, Melton LJ 3rd, et al. Increased cardiovascular mortality after early bilateral oophorectomy. Menopause. 2009;16(1):15-23.
57. Mack WJ, Slater CC, Xiang M, Shoupe D, Lobo RA, Hodis HN. Elevated subclinical atherosclerosis associated with oophorectomy is related to time since menopause rather than type of menopause. Fertil Steril. 2004;82(2):391-397.

58. Archer DF. Premature menopause increases cardiovascular risk. Climacteric. 2009;12(Suppl 1):26-31.

59. Howard BV, Kuller L, Langer R, Manson JE, Allen C, Assaf A, et al. Women's Health Initiative. Risk of cardio- vascular disease by hysterectomy status, with and without oophorectomy: the Women's Health Initiative Observational Study. Circulation. 2005;111(12):1462-1470.

60. Rossouw JE, Prentice RL, Manson JE, LieLing Wu, David Barad, Vanessa MB, et al. Postmenopausal hormone therapy and risk of cardiovascular disease by age and years since menopause. JAMA. 2007;297(13):1465-1477.

61. ELITE Trial.ClinicalTrials.gov Identifier: NCT00114517.

62. Hodis h, Wendy J. Mack, Victor W. Henderson, Shoupe D, Budoff M, Azen SP for the ELITE Research Group. Vascular Effects of Early versus LatePostmenopausal Treatment with Estradiol. NEJM. 2016;13:374:1222-1231. 